\title{
Keyworking in residential child care: Lessons from research
}

\author{
Orla Cahill, Stephanie Holt* , Gloria Kirwan \\ School of Social Work E' Social Policy, University of Dublin, Trinity College, Dublin, Ireland
}

\section{A R T I C L E I N F O}

\section{Article history:}

Received 23 December 2015

Received in revised form 15 April 2016

Accepted 16 April 2016

Available online 19 April 2016

\section{Keywords:}

Residential care

Relationship based practice

Keyworking

Outcomes

\begin{abstract}
A B S T R A C T
Developing quality relationships is recognised as an active ingredient for effective interventions with young people in care. Essentially, care staff has the opportunity and capacity to positively influence the young person's experiences in care, through the positive relationships they form. This paper presents selectively on the findings of two separate but related qualitative Irish studies exploring relationship-based approaches in residential child care practice, from the perspectives of both residential child care workers and young care leavers. Thirty-two professionals and four care leavers participated in either focus group or individual interviews. The findings are integrated in this paper with the wider literature on young people leaving care, with the aim of identifying core knowledge that is needed by service providers who are tasked with the support of young people making the transition out of care and towards independent living. In this paper we attempt to identify the knowledge base on relationship-building which is needed by care staff in order to carry out their role. It is argued that an explicit knowledge base is overdue now that the complex needs of young people in care are increasingly visible through advances in research and more recently the emerging literature concerning the personal testimonies of care graduates.
\end{abstract}

(C) 2016 Elsevier Ltd. All rights reserved.

\section{Introduction}

A wealth of international research conducted over the last three decades exploring outcomes for young people in state care has highlighted a disturbing trend of poor outcomes across a range of indicators (Berridge, Biehal, Lutman, Henry, \& Palomares, 2011; O'Higgins et al., 2015). These disappointing trends are not confined to Ireland, and Bullock, Courtney, Parker, Sinclair, and Thoburn (2006) make the observation that in both the United Kingdom and the United States studies reveal a consistent pattern of poor outcomes for care system graduates. While this evidence is drawn from the children in state care more generally and does not refer specifically to children in residential care, selected evidence from England (Bilson, Price, \& Stanley, 2010; Dixon, 2008; McAuley \& Davis, 2009); Scotland (McClung \& Gayle, 2010); France (Dumaret, Donati, \& Crost, 2011); Northern Ireland (McCrystal \& McAloney, 2010); Australia (Townsend, 2012); USA (Pears, Kim, Fisher, \& Yoerger, 2013), nonetheless points consistently to poor educational achievement, poor physical, mental and general well-being, homelessness, criminality, unemployment, teenage parenting and poor social networks. While research to date highlighting the success of care-leavers is relatively scarce (Martin \& Jackson, 2002), what is known points consistently to the importance of stability, not solely related to stability of placement setting but also more significantly the importance of positive and stable relationships with professionals involved in their care (Dumaret et al., 2011; Martin \& Jackson, 2002;

\footnotetext{
* Corresponding author.

E-mail address: sholt@tcd.ie (S. Holt).
}

McLeod, 2010). Indeed Berridge et al. (2011) concluded that relationships may be a key factor in successful interventions with such young people.

Grounded theoretically in 'relationship-based practice' (Ruch et al., 2010), the practice of keyworking is founded on the idea that human relationships are of paramount importance and a fundamental need for human beings. Bowlby (1952, as cited by Munro, 2002) asserted the importance of secure and sensitive relationships throughout childhood in order for a person to develop into a "happy well-balanced adult" (Munro, 2002; 39). Young people receiving care within their own homes develop bonds with their carers, most often their natural parents, which can continue across the lifespan. Conversely, in residential care units these bonds are established with paid personnel and they are relative to staff shift work (Jones, Landsverk, \& Roberts, 2007). As such, the ability to establish a positive relationship with clients is a fundamental tool for service providers working in the helping profession (Woods \& Hollis, 2000), considering their work begins and ends with a human encounter. The relationships developed between care staff and young people differ from other forms of relationships experienced by the young person. This relationship is not indefinite and does not hold continuous emotional bonds such as a parent-child relationship (Munro, 2002).

Developing quality relationships is recognised as an active ingredient for effective interventions with young people. Essentially, care staff has the opportunity and capacity to positively influence the young person's experiences in care, through the positive relationships they form. Morrison's (2015) positive account of her journey through care, aftercare and into a professional caring role underscores the 
knowledge base available to and required by service providers if they are to successfully support young people living in care or in the process or transitioning out of the care system. Her strengths and resilience are impressive as is her capacity to insightfully reflect on the positive and negative sides of her cared for experiences and to channel the totality of her life in a very positive direction. Unfortunately, for many young people leaving care the outcomes, at least initially, are less positive.

This paper integrates the findings of two separate but related Irish studies exploring relationship-based approaches in residential child care practice, from the perspectives of both residential social care workers ${ }^{1}$ and young care leavers with the wider literature on young people leaving care, with the aim of identifying core knowledge that is needed by service providers who are tasked with the support of young people making the transition out of care and towards independent living. In this paper we attempt to identify the knowledge base on relationship-building which is needed by care staff in order to carry out their role. It is argued that an explicit knowledge base is overdue now that the complex needs of young people in care are increasingly visible through advances in research and more recently the emerging literature concerning the personal testimonies of care graduates such as Morrison (2015).

\section{Context for the research}

There have been a number of key shifts in the function, organisation and delivery of residential child care in Ireland as in other jurisdictions. Traditionally, the pattern of child care services in Ireland placed great influence on institutional care. The institutional care provided largely involved placements for youth offenders known as reformative schools placements for those who were neglected, orphaned or abandoned called industrial schools, which were established under the Reformatory Schools Act 1858 (O'Sullivan, 2014). Reformatory and Industrial Schools were large-scale institutional buildings that catered for large numbers of children and were managed by either Catholic religious congregations or voluntary organisations. These institutions were also geographically isolated (Williams \& Lalor, 2001). There were approximately 71 industrial schools in Ireland in the 1960s (O'Sullivan, 2014).

These institutions remained essentially unchanged until the publication of the Report of the Committee Enquiry into Reformatory and Industrial Schools Systems (Department of Health, 1970, better known as 'The Kennedy Report). The Kennedy Report (1970) was an important catalyst in the history of residential childcare in Ireland, creating an awareness of the needs of deprived children (Skehill, 2005) and leading to the closure of the Industrial and Reformatory schools and initiating the change from large single sex isolated institutions to the development of small group homes in the community (Williams \& Lalor, 2001). The Kennedy Report (1970) also recommended that residential care should be considered only when there are no satisfactory alternatives.

Gilligan (2014) observes that from the 1860s to the 1969s, residential childcare reflected a general propensity in Ireland as elsewhere, to depend largely on institutional care to conceal what were considered our social problems. Throughout this period, the number of children in alternative care, particularly in residential care was high, with approximately 3000 young people placed in various form of residential care by the mid 1960's (O'Sullivan, 2014). During the mid-1950s the number of children in alternative care began to drop. However from the 1980's onwards, this number has being steadily rising with currently an

\footnotetext{
${ }^{1}$ In the Irish context, previous titles for professionals working in residential child care, such as 'child care worker', 'residential child care work' and 'residential care worker' were replaced with the title 'social care worker' under the Health and Social Care Professionals Act (2005). This title infers professional training and will be legislated for when social care workers are mandated on to the Health \& Social Care Regulatory Board in 2016 following the introduction in 2015 of the Social Care Workers Registration Board.
}

approximate of 6420 children in state care (Department of Children and Youth Affairs, 2015). While the overall number of children in care has continued to grow from the mid-1980s onwards, the preferred care placement shifted decisively from residential care to foster care (O'Sullivan, 2014). By 1980, there were slightly more children in foster care than residential care; in contrast, in 2013 (the latest available figures for children in care) $93 \%$ of all children in state care were placed in either general or relative foster care (Department of Children and Youth Affairs, 2015) and just 5\% of that population placed in residential childcare. O'Sullivan $(2009 ; 21)$ concludes that:

"the role of residential care has moved from a position of dominance in the provision of alternative childcare in Ireland to now being a residualised and specialised service".

The most up to date data published by TUSLA (2016), the National Child and Family Support Agency, indicates that at the end of December 2015, 327 children were living in residential care facilities and 16 were in special residential care facilities, amounting to a total number of 343 children in residential care within the Irish State. An additional 4 children were reported as placed in secure residential facilities located outside the state. In contrast, 4100 children were recorded living in foster placements in December 2015 with an additional 1832 children residing in approved extended family foster care arrangements, bringing the total number of children living in foster care settings to 5932 in total. In percentage terms, this calculates as $94.5 \%$ of children in care are placed in foster care arrangements and $5.5 \%$ of the total number of children in care are living in residential care settings in Ireland. These figures do not include children who are living in private arrangements away from their natural family. ${ }^{2}$

In the literature, the roles and responsibilities of the residential social care workers have received increased recognition, consequently highlighting the complexity of the care work task (Williams \& Lalor, 2001). Traditionally, in the Irish context, individuals working in the early industrial homes were untrained with little or no professional development opportunities (O'Sullivan, 2014). The Kennedy report (1970) emphasised that there was a lack of awareness of children's needs in the industrial homes and that this was a consequence of the lack of professional training in child care (Gilligan, 2014). Subsequently, there was a shift in the qualification of child care staff from basic vocational training to professionally trained and recognised care workers (O'Sullivan, 2014). The introduction of legislative initiatives such as the 1991 Child Care Act and The Standards and Criteria for the Inspection of Children's Residential Centres 1999 further increased the need for appropriate training of care staff and high standards of professional practice among social care workers (Williams \& Lalor, 2001). Currently there has been an increased focus on the social care role and related knowledge base with the enactment of the Health and Social Care Professionals Act 2005 which has led to the establishment of CORU (the Health and Social Care Professionals Council), which has oversight of regulatory matters related to social care as well as professional accreditation. The aim of the legislation is to ensure that a high quality standard of performance is maintained across a range of health care professionals, including social care workers and to offer the public protection from individual professionals who display incompetence or worse. To date, CORU (2016) has not opened the Social Care Register due in part to ongoing preparatory work aimed at achieving agreement on the criteria for approval of educational programmes and a national set of proficiency standards for the profession. Therefore, at present, social care and the education of prospective social care workers is in a period of transition as it moves towards a regulated workforce and an agreed educational curriculum.

\footnotetext{
${ }^{2}$ For more information on residential child care services in Ireland, please visit http:// www.tusla.ie/services/alternative-care/residential-care/what-are-childrens-residentialservices/.
} 
Regarding the provision of Aftercare in Ireland, Section 45 of the Child Care Act 1991 placed a statutory duty on Tusla (the Child \& Family Agency) to form a view in relation to each person leaving care as to whether there is a "need for assistance" and if it forms such a view, to provide services in accordance with the legislation and subject to resources. Criticisms of the legislative status of aftercare in Ireland primarily centered around the wording of the act, with a provision for a more implicit and enabling 'may' provide aftercare services rather than a more explicit and obligatory 'should' provide the same (reference). On 10th December 2015, the Child Care (Amendment) Act 2015 was signed into law by the President of Ireland. The main purpose of this legislation is to strengthen the legislative provisions for aftercare by amending the Child Care Act 1991 to place a statutory duty on the Child and Family Agency (Tusla) to prepare an aftercare plan for an eligible child or eligible young person. The research upon which this paper is based was conducted prior to the introduction of this new legislation.

\section{Literature review}

The literature review presented here addresses the nature, meaning and the importance of relationship-based practice and its relevance to the residential child care profession. An overview of keyworking, its definition and potential and the challenges to relationship building with young people in residential care will also be considered.

\subsection{Relationship based practice}

Relationship-based approaches have attracted considerable commentary and research with Turney (2012: 150) asserting that the resurgence of interest in relationship-based practice is reflective of an acknowledgement that "the downplaying of relationships has led to serious gaps in practice". This can be seen in Cooper's (2005) analysis of the Victoria Climbie case in the UK which illuminates the significance of the relational element of the caring profession and highlights the importance of developing positive and consistent relationships with the young people concerned.

According to Howe (1998a), the level of an individual's social understanding is reliant on the quality of their relationship history, arguing that the value of the young person's relational experience has profound effects on their social-emotional development, personality formation and social competence. Indeed, where relational difficulties abound, a breakdown in a person's ability to sustain healthy relationships with others can result (Trevithick, 2003). Howe asserts that "if poor relationships are where psychological competences go awry, then good relationships are where they are likely to recover" (Howe, 1998b). In similar vein, research conducted on attachment asserts the importance of relational experience in early childhood on the development of personality and personality disturbances (Bowlby, 1969; Fonagy, 2002). This framework describes the dynamics of relationships between humans throughout the lifespan (Howe, 1995). According to Payne (2005) the attachment experienced in early childhood acts as an important foundation for later social competence, can help with providing links between an individual's emotional development and behaviour and is crucial to their development and well-being. Thus, this theoretical framework can be used as a base to increase professional's understanding of the development of behaviours of young people (Daniel, Wassell, \& Gilligan, 2010).

\subsection{Young people, state care and the importance of relationships}

Many children and young people in the care system have experienced severe adversities over a prolonged period of time or intermittent patterns (Perry, Pollard, Blakley, \& Vigilante, 1995). However, it is essential to acknowledge that these young people are not a homogenous group (Dixon \& Stein, 2005; Kendrick, 2008; Owusu-Bempah, 2010), the quality of their care and early family experiences that have resulted in their reception into the care system reflect diverse backgrounds (Pinkerton, 1999). Nevertheless, the presence of emotional and psychological problems among children who have experienced abuse is well documented (Perry et al., 1995; Flores, Cicchetti, \& Rogosch, 2005; Cicchetti and Rogosch, 1997; Frederico, Jackson, \& Black, 2008.). A consistent finding is that children and young people subjected to abuse and neglect may experience multiple and interrelated consequences (Bailey, Thoburn, \& Wakeham, 2002). Cicchetti and Rogosch (1997) delineate the multiple damaging features that exist in children subsequent to abusive home environments, including rejection and aggression which consistently produce insecure attachments. According to Howe (1995) it can cause young people to become distrustful towards other adults, difficulty in understanding the emotions of others and forming and maintaining relationships. Poor and damaged attachments can be further compounded negatively by difficulties experienced maintaining family ties once in care (Holt \& Kirwan, 2012).

Research also identifies that there are certain protective factors pertaining to the child which may mediate the effects of adversity experienced (Gilligan, 1999; Daniel \& Wassell, 2002). According to De Boer and Coady (2007), outcomes for services users in general are linked to the quality of the worker/service user relationship. Echoing these sentiments, Houston's $(2010,2011)$ research in Northern Ireland highlights the importance of relationship building as a medium for building resilience in young people. Gilligan $(1997 ; 12)$ defines resilience as "qualities which cushion a vulnerable child from the worst effects of adversity... and may help a child or young person to cope, survive and even thrive in the face of great hurt and disadvantage". The concept of resilience offers an alternative framework for intervention by focussing on potential areas of strength within the young person's ecological system. According to Gilligan (1999) achieving improvements in parts of the young person's life can have positive "spill over" effects into other parts. Gilligan (1997) further argued that the potential of young people to be successful graduates of the care system can be enhanced by giving attention to activities in the young person's life. However, this process required more than the pursuit of an activity; it involved sensitive and natural mentoring from a concerned adult (Gilligan, 1999). Gilligan asserts that "the value also lies in the recognition that performance of the activity may earn, the relationships it may open up and the confidence it may generate" (Gilligan, 1999). Cashmore and Paxman's (2006) research illuminated the complexities of the lives of young people who are cared for out of home and how security of relationships was a fundamental plank in helping the young people they interviewed in mediating the experience of separation from their family of origin. Shaw's (2014: 154) study suggests that young people receive a better quality of care when care staff acknowledge and take into account the impact of the young person's pre-care history and relationship experiences. Echoing Jackson and Martin (1998) assertion that the presence of a special relationship with at least one person as an important factor for fostering resilience, Morrison (2015: 7) reflects on the contribution that 'warm relationships' made in her successful care journey.

Daniel (2003) argued that using a resilience-based framework provides potential for a residential care unit to act as a secure base if the young person experiences the relationship as reliable, permitting staff to become part of the young person's support network. This approach concentrates on building protective and supportive networks around the young person, but also nurturing the existing areas of strength within the child (Miller \& Daniel, 2007).

\subsection{Residential care and the keyworker role}

The general premise underlying residential units is to promote a benign human relationship that creates the environment of safety and growth (Health Service Executive, 2012a). The European Association of Research into Residential Child Care (EUROARRCC, 1998) report identifies the provision of quality residential childcare as a multifaceted and complex task, involving a crucial balance between meeting each young 
person's need for physical care, emotional support as well as his/her need for therapeutic care and support in light of the specific adversities that have led to their admission to the care system. It is the task of social care workers to create the type of environment as outlined above while simultaneously applying agency policies and rules (Watson, 2002). Sinclair (2006) suggests that social care workers are required to balance risk and needs of young people, exercise care and control and manage the personal and professional interface.

Across the residential sector in Ireland, best practice is regarded as the provision of individualised care for each young person in a residential centre by a certain member of staff who is referred to as a keyworker (HSE Dublin North East, 2010). In terms of keyworking as a concept, Mallinson (1992) illuminates the different aspects of keyworking that include coordination of the care plan for individual residents as well as meeting the needs of individual residents for "personalised relationships" within the unique environment of residential care group, developing and maintaining trusting relationships with the young people. By engaging in this trusting relationship, the keyworker is to help the young person understand the purpose of their placement, assist them in their recovery from the adversity that precipitated their reception into care and to provide them with positive role models to enable the development of pro social learning (HSE Dublin North East, 2010: 24).

Byrne and McHugh (2005) highlight as primary the role the keyworker plays in helping the young person "make sense" of the experience of living in residential care settings, and they cite Clarke's (1998, p. 31) observation on the potential for keyworking to "improve personalised care, relationships, the clarity of the residential tasks". Stevens (2004) and Clarke (1998) acknowledge that young people placed in alternative care present many complex issues that require skilful and knowledgeable interventions from their care giver. Shealy (1995) supports this and states that in order for children to "heal and develop" they require "knowledgeable, empathetic and skilful therapeutic interventions" (1995; 567).

Although a wealth of evidence base exists regarding the importance of quality relationships for young people in residential care, research has also identified the barriers to building these positive relationships.

\subsection{Challenges to developing relationships with young people in residential care}

Gaskell (2009) cites a number of factors that can impact negatively on the formation, quality and endurance of positive relationships between young people in care and their caregivers. These include a young person's prior negative history of relationships, either experienced prior to their admission to care or in the context of other caredfor settings; the difficulties in overcoming any lack of trust that the young person feels towards adults in their life; the unsettling impact of constant moves and placement instability, too often a feature of the care histories of young people living in residential care; and, finally, the problem of staff retention and the recurring theme of high staff turnover in many residential care settings that mitigates against continuity, security and trust, all central characteristics of felt security and positive relationships between staff and young people in care.

De Boer and Coady (2007) posit that there are many obstacles practitioners face when working in the child welfare profession. The very nature of residential care work offers unique challenges to the development and maintenance of positive relationships. Previous studies have identified that conflict and offending behaviour are more common in residential care settings than other type of care placements (Shaw, 2011), which can cause mutual reinforcement of antisocial behaviours (Sinclair \& Gibbs, 1998) among the young residents. Barter et al. (2004) large UK study on peer violence in residential homes also highlighted this behaviour as a potential negative influence on staffchild relationships, particularly in the absence of a clear understanding of why such violence occurs and trained staff capable of responding appropriately and effectively. Writing in the UK, Sinclair (2006) suggests that the primary function of residential care settings is to provide accommodation for young people who cannot be managed in other ways, subsequently causing residential units to become known as "last resort" placements, primarily catering for children who are hard to place elsewhere (Smith, 2009). Reflecting on how residential childcare has developed in an Irish context, Gilligan (2014) similarly posits that institutional childcare is now almost exclusively responding to the needs of children and young people considered outside the ability of other care options to deal with.

This "last resort" status of children's care homes means that some of society's most vulnerable and troublesome young people with more challenging behaviours, can present a struggle for care workers to sustain the group experience as a positive one (Smith, 2009). It is the task of the care staff to provide a safe and nurturing environment for young people by managing the risk through surveillance as well as engaging in and promoting positive relations with the residents.

\section{Methodology}

As stated earlier, this paper draws selectively on the findings of two separate but related Irish studies (referred to in this article as S1 and S2) that explore relationship-based approaches in residential child care practice, from the perspectives of both residential social care workers and young care leavers. The first study (S1) accessed participants through the National Residential Child Care Managers Forum. With permission from that Managers Forum, three residential units were approached and agreed to participate in the study. These units were all located in one urban setting and included two long term units for boys and one short-term crisis unit for girls. A total of twenty keywork staff working in these three targeted units participated in three focus group interviews. The targeted involvement of gate-keepers also involved approaching two further organisations: the National AfterCare Workers Forum and a second national organisation advocating on behalf of young people within and graduated from the Irish care system. A further three aftercare workers were accessed through these two gate-keeping organisations and participated in individual interviews. Four young people were accessed through these gate-keeping sources and participated in one group and one individual interview. While a number of other young people had indicated their interest in participating in the research, they did not however present themselves for scheduled and subsequently rescheduled interviews. A number of writers have highlighted the challenges often encountered in recruiting young people living in residential homes as research participants (Kendrick et al., 2008; Emond, 2005). It is possible that some of these factors, such as a reluctance to discuss painful life events, persisted into the aftercare environment and were compounded by the often chaotic lives of vulnerable care leavers can perhaps go some way to explain the low numbers who actually engaged in the study (Daly, 2012). The profile of the participating young people includes two male and two female care leavers between the ages of 21-24 years of age. Their care careers spanned between three and thirteen years in state care, predominantly but not exclusively within the residential care sector, involving between one residential care setting experience to multiple moves and experiences.

Regarding the second study (S2), eight social care workers from one unit working with boys were purposively recruited for participation in the study and a stakeholder with an expertise in aftercare was also directly recruited through the Aftercare Workers Forum. A focus group was conducted with the residential care staff and an individual semistructured interview conducted with the stakeholder. All interviews were digitally recorded with the participants' permission and transcribed verbatim.

As a perquisite to research activity in the institution under whose auspices both of these studies were carried out, full ethical approval was sought from and granted by the Research Ethics Approval Committee. 
In this article, when direct quotes are presented, the participant will be referred to by their role title and research number and also by S1 or S2 to indicate in which study their interview was located. For example, 'Care Worker 1, S1' indicates that the quote is from a care worker who was assigned the number ' 1 ' in the study in which they participated and $\mathrm{S} 1$ indicates that they participated in the first study of the two studies reported on in this article.

\section{Findings}

Emerging from the findings of these two studies was evidence of a consistent understanding and acknowledgement of the importance for young people in residential care, to form constructive and supportive relationships with their caregivers. All of the participants acknowledged that it is at the heart of their practice, as captured in this quote:

It's key [the relationship], you couldn't do the work if you didn't have relationships with them, the house would be in crisis and chaos... it's what it comes down to, It's so hard to do any sort of work if you don't, there is no trust or respect or anything there (Care Worker 8: S2)

Running parallel with that was ample evidence that building positive relationships with young people in residential care is a fundamental role for social care workers, with participants viewing keyworking as a positive method of facilitating the establishment and continuation of supportive relationships. Generally, as reflected in the following quote, the participants explained keyworking as a feature of a wider relationship-based approach operating in their work setting.

Key working is based on a relationship based approach. I believe everyone working here has to have a relationship with the young people, though it can be difficult at times. (Care Worker 1: S1)

Participants across both studies also identified a number of what they described were key ingredients to the successful development of relationships with young people in residential care.

\subsection{Key ingredients}

The factors considered to be the key ingredients for relationships with young people in residential care to be developed included the environment of the residential unit, the amount of time devoted to building relationships, and various aspects of the professionals involved, including the professional's skill base and knowledge, their personality and skills and importantly their genuineness or congruence, as experienced by the young people in their care.

The participating care providers consistently highlighted the importance of generating a nurturing environment which helped young people develop roots or a sense of belonging to the residential setting. Even for those who worked in short-term and crisis intervention services, there was an acknowledgement of the importance of continuity across the young person's life. Keyworking was viewed as a useful method of providing continuity and a sense of belonging for the young person, as captured in this quote:

We are his family, his memories, the past, his identity, his support, unconditionally, this is his home. Care Worker 2: S1)

The narrative of the young person referred to in the above quote who also participated in this study, similarly reflected a potent bond with his residential unit, resonating with the significance of 'secure base' and 'felt security' referred to earlier. This next quote illustrates these themes:

This is my home, this will always be my home. They are my family life 'cos they are always here if they say they are going to be. (Care Leaver 1: S1)
Furthermore another participant identified safety within the care home as a primary ingredient. She asserted that:

If the house is in chaos and people are being assaulted, it would be very hard to open up and be yourself and move into a kind of intimate relationship with people because they [young person] would have to have their defences up so I think the house has to be safe to have a relationship (Care Worker 3: S2)

Time was a potent theme emerging across both studies, with workers highlighting the time it can take to understand the young person's journey prior to their reception to the unit and getting to know them while in the care home. They asserted that having this understanding helped them to identify the most appropriate approach to work with the young person.

Furthermore, the participants also identified that building quality relationships can be dependent on the length of time the young person remains in the unit, as it:

...depends on partly how long you have to work with them how long they will be here (Care Worker 4: S2)

Some participants expressed that a "relationship takes time and is not something that can be forced" (Care Worker 6), but that it is also something that can be opportunistic, as captured in the following quote:

Even if a young person is avoidant... usually when things aren't going so well for them, and that's where we will be because we know that we are very good at supporting them in that kind of situation and that's often where even the ones that avoid you..they start to tell you what's going on, they get the experience of being listened to and people being trust worthy (Care Worker 3: S2)

All participating care workers asserted that having a genuine interest in building a relationship, respecting and accepting the young person and acting in a congruent and transparent way were reported as fundamental ingredients to developing positive relationships with young people in their care. The following quotes illustrate how one care worker developed a positive relationship with a young person, who was initially very avoidant towards staff:

She didn't try and change him... [she was] accepting in some ways... and we were just there for him when he came home (Care Worker 2: S2)

\section{...He felt she cared (Care Worker 3: S2)}

In addition, it also emerged from both participating young care leavers and care providers that young people in care can easily identify both congruence and indeed incongruence in the relationships they have with their care providers. The following quote captures one young person's recollections of the array of relationships he experienced with care givers:

You know automatically the ones that are just coming here to work, that don't really care about you - the ones who just come in here to get paid - and the ones who do [care], you can see it in the work they put into you; they care about the outcome of the work they do with you; [they] don't bullshit you. You know, like doing your family life story work - like we went out to where I grew up, that's the good part of doing all that, going back to your roots. Some people will say it is too hard for them, but you have to do it. (Care Leaver 1: S1)

Concurring with this, Care Worker 8 (S2) asserted that "they know if you genuinely care or not".

Across the number of service providers interviewed in both studies, was a consistent finding of the importance of using their personal skill base and interests when building relationships. The participants viewed 
the personal characteristics of each staff member as a positive element of facilitating the establishment and maintenance of quality relationships with young people. Care Worker 1(S2) furthered that it is about recognising that different people are comfortable at different behaviours and that staff and young people collectively develop their relationship along different roots, further asserting that it is important for staff to also "be aware of their strengths and weaknesses and do what you can".

This was supported by Care Worker 4 (S2) who highlighted that the element of personality and characteristics is recognised within the management of keyworking and the matching of a key worker and young person is arranged with reference to their personality and their relationships. In agreement Care Worker 1 asserted:

Eventually the child will identify someone, more often than not that they just enjoy being around, that they get something from be it their humour or maybe the nurturing that they receive that they are comfortable with. So from there, that sort of first light attachment, that's where it starts. (Care Worker 1, S2).

How a key worker is assigned to a young person also emerged as an impediment to the developing of relationships as the next section outlines.

\subsection{What impedes the relationship?}

Across both studies, while the participants asserted the importance of establishing relationships with young people, the challenges to doing so were also identified. Participating young people reported difficulty trusting care staff for a number of reasons, including previous abusive relationships in their earlier lives; staff turnover; lack of consultation regarding change of keyworker; and multiple placement disruptions experienced over a relatively short time period, which set them on a trajectory of repeated short-term placements in a variety of settings.

Gender was an additional factor which most of the participating young people raised as an issue that they found inhibited the formation of relationships with their keyworkers. Both male and female care leavers reported incidences of being assigned keyworkers of the opposite gender to their own, and for a variety of reasons finding this a difficult experience. For example, some reported that they felt they had not been included in the decision about who would be their keyworker. Others recalled experiencing significant discomfort with a keyworker of the opposite sex because they were at the age of puberty and reported finding it very difficult to ask questions about the physical and emotional changes they were experiencing. The female care leavers reported additional embarrassment in asking a male keyworker for help with obtaining personal hygiene items. However, males in the study also reported problems with asking female staff about bodily changes to the point that one young man recalled working up the courage to approach the only adult male he regularly had contact with about why his body was changing. This person was his school teacher as in his residential unit at the time all the staff (and all the other residents) were female.

A smaller number of the young people interviewed alluded to histories of abusive relationships in their early childhood which compromised their ability to establish keyworking relationships with members of the opposite sex. The young people we interviewed, when asked how the issue of gender or any other problematic factors could be addressed when assigning keyworkers to young people in care, all stated that the missing link had been consultation with them before their keyworker was assigned. The following extract from one of the interviews captures both the potential benefits of a successful keyworking relationship with a worker of the same gender as well as the additional distress which results from an unwanted change in the key working relationship:
For the first couple of years I had a female keyworker... it was great cos I never had the mother figure and then she decided that she just didn't want to do keyworking anymore. And I remember being really upset, really upset, really really really upset because then they told me that I was getting a man for a keyworker. I couldn't hack it. It set me a million miles back. (Care Leaver 3: S1)

The participating professionals across both studies highlighted that the backgrounds of young people coming into residential care can pose a challenge to the relationship formation. The care workers also identified that the developmental stage of young people can serve as a challenge to forming positive relationships. The experiences that young people bring with them into the unit add to these challenges. The following quote illustrates this:

They bring everything from the moment they were born into this world to the moment they come here, every experience they had, so if they had negative experiences at home or at school or their foster places they bring that with them (Care Worker 3: S2)

The inability to develop the relationship has implications for the young person to have a relationship that endures and extends past their residence in the unit. It was evident in their commentary that the care workers interviewed placed importance on helping young people develop relationship skills. A similar finding is reported in the study by Berridge et al. (2011) where staff, educated as social pedagogues, talked about working to help young people build trust and develop caring relationships as part of their focus on empowerment of the young people in their care. Many occurrences were illuminated through the care workers discussion of instances where the relationship between the young person and a care worker endured well into the post residence period. The next section presents the findings on this theme.

\subsection{Post care relationships}

The value placed on after care contact by all of the participants was evident throughout the fieldwork. While as stated earlier, the Irish State is legally mandated since 2015 to provide Aftercare services, that new development in the legislation post-dates the research upon which this paper is based. The provision of aftercare was nonetheless highly valued by the participating care workers and by the organisation they worked in. The following quote illustrates this:

They become part of (Residential Unit), (Residential Unit) becomes their family home for them and they can come back here in different shapes and forms. There is a sense that (Residential Unit) is always here for you [the young person] regardless of where you are at in your life (Care Worker 1: S2)

Many instances were illuminated across both studies, of the value placed on aftercare contact, not only by the young care leavers who embraced this ongoing support, but also by the keyworkers, who acknowledged their sometimes conflicting feelings around the move of the young person out of their care into an often challenging and at times hostile world, as this worker explains:

of course you worry, you worry because you care and because you know what they have been through. To some degree you have to let go, to have energy and space for the other kids coming though, but it is great when they come back and are doing ok. (Care worker 5: S1)

Reflecting on 'readiness' for independence, one care leaver recalled leaving his residential unit once he reached 18 years of age and was no longer formally in the care of the state, even though he was preparing for his final school examinations:

I wanted to go, I was ready. Like I could have stayed here until I was finished School but I chose to leave when I was in 6th year, so when I was 
18 , in 6th year, I was living by myself. I loved living by myself and the time was right and it just worked out. They told me I could stay here till I finished (school) and that was sound. (Care Leaver 1: S1)

The importance of preparing for leaving care and independent living is further commented on by this young care leaver, who explained the significance of his key worker in this regard:

From about 16 keyworking was great 'cos it was all about getting ready for leaving. A few months before I went they gave me the key of the door and the alarm code. That meant a lot, the trust, it was like a normal family...well almost. (Care Leaver 1: S1)

The capacity of the residential care setting to act as a potential buffer against the post-care vulnerabilities such as loneliness, stress and poverty was also clearly reported on in this study. Care leavers described regular Saturday or Sunday visits for the evening meal with more infrequent visits to the residential unit for assistance with job applications, telephone use and emergency food supplies. Of particular significance was the link with the residential unit and the residential keywork staff, described by both participating staff and young people as providing a vital sense of continuity between their past, the present and their future. Finally, the importance of the connection to the residential home and the significance of the tie to both people and place is poignantly reflected on and articulated by this participating care leaver:

Like 'leaving care', what does that mean? You don't say 'leaving home', you just say moving out. I've moved out of here and I know I am not in care now, but I haven't left here. (Care Leaver 1: S1)

\section{Discussion}

Research identifies that relationships are a reciprocal process that is influenced by personal qualities, attributes, skills and knowledge base (Trevithick, 2003). This description of relationships resonates with the findings of this paper which highlighted that the relationships built with young people in care are highly influenced by their personal characteristics and all the experiences the young person brings with them. Pre-care experience of abuse, neglect and other forms of adversity can have an impact on the young person's developmental and social functioning and also their ability to develop future relationships, which the young person can carry through their care career (Flores et al., 2005). Furthermore, it is likely that young people in care have entered and journeyed through the care system experiencing poor attachments with their family of origin (Holt \& Kirwan, 2012). Consequently, their capacity to develop and maintain meaningful relationships with young people in their care is dependent on the young person's ability and acceptance to build such relationships. The participants highlighted that some young people can present as avoidant and fail to engage in meaningful relationships with them, they furthered that young people have to genuinely want to build a relationship with the care staff.

Both studies reported on in this paper concur in identifying relationship-based practice as a critical role for social care workers, highlighting that in reality, this process can be undermined by a number of elements. This paper proposes that relationships are not only integral to keyworking but are also inextricably linked to successful transitions. As such, keyworking not only has the potential to build relational capacity but also the opportunity to do so, an opportunity perhaps heretofore unavailable to many young people needing alternative care. Critical to achieving optimum keyworking relationships however, is the process of matching keyworker to young people, which includes consultation with the young people themselves and the supervision and training of keyworkers as a vital support for staff.

An important finding from the present study was that the characteristics of the young people in residential care are not viewed in isolation as an influencing factor for the formation of working relationships.
Equally, the circumstances and the characteristics of care workers are also influential in the relationship process. There was a consensus across both studies represented in this paper that staff characteristics are also a key a contributing factor. All participants further acknowledged that being genuine is a key ingredient to establishing a positive relationship with a young person. Clarke's (1998) assertion that the knowledge, skill and characteristics of the staff play a vital role in the day to day care of young people, was further supported by the research reported in this present study. Significantly, the participants acknowledged the importance of professional knowledge from theoretical base and also utilising their personal attributes and experiences in the relationship process. Furthermore, the importance of matching the young person with a staff member for keyworking in accordance to the young person's and the care worker's relational bond was also highlighted.

\section{Conclusions}

This paper has illustrated that the relationship based approach in residential care practice is grounded in the knowledge and skill base of the care worker along with characteristics and circumstances of both the care worker and the young person. Although these elements were identified as important for enhancing relationship-based practice, they were also considered factors that can mitigate against the quality of relationships formed. The ability to achieve relationship-based practice in residential child care units relies heavily on both the young person's background and circumstances and also the personality of the staff and their capacity to positively engage with such individuals. The key message of this paper is that it is important for care workers to have an awareness of the potential impact of their personal circumstances and traits has on the relationship with the young person, to be supported in their role and to constantly strive to create an environment where quality relationships can evolve.

Finally, young people in care do not conform to a one size fits all profile. They are individually unique, each possessing their personal set of needs and strengths, which will not remain a static picture for any one person over the course of time. Keyworkers, charged as they are with the task of supporting young people both during their time in care and in the transition period out of care, need a well-developed knowledge and skill base if they are to offer this group of young people the help, assistance, support and guidance which they need and deserve. This article has taken tentative steps in trying to formulate an overview of the different types of knowledge and skills which can underpin the keyworker role. We hope this is the beginning of a much wider conversation on the knowledge base of keyworking and how best to prepare for and support workers who take on this exceptionally important role with young people in care.

\section{References}

Bailey, S., Thoburn, J., \& Wakeham, H. (2002). Using the 'Looking After Children' dimensions to collect aggregate data on well-being. Child E family social work, 7(3), 189-201.

Barter, C., Renold, E., Berridge, D., \& Cawson, P. (2004). Peer violence in children's residential care. Basingstoke: Palgrave MacMillan.

Berridge, D., Biehal, N., Lutman, E., Henry, L., \& Palomares, M. (2011). Raising the bar? Evaluation of the social pedagogy pilot programme in residential children's homes. Department for Education (UK)

Bilson, A., Price, J., \& Stanley, N. (2010). Developing employment opportunities for care leavers. Children \&' Society, 25(5), 382-393.

Bowlby, J. (1969). Attachment and loss: Volume 1: Attachment. London: Horgarth Press.

Bullock, R., Courtney, M. E., Parker, R., Sinclair, I., \& Thoburn, J. (2006). Can the corporate state parent? Children and Youth Services Review, 28, 1344-1358.

Byrne, J., \& McHugh, J. (2005). Residential childcare. In P. Share, \& N. McElwee (Eds.), Applied social care: An introduction for Irish students (pp. 313-320). Dublin: Gill \& McMillan.

Cashmore, J., \& Paxman, M. (2006). Predicting after-care outcomes: The importance of 'felt' security. Child and Family Social Work, 11(3), 232-241.

Cicchetti, D., \& Rogosch, A. D. (1997). The role of self-organization in the promotion of resilience in maltreated children. Development and Psychopathology, 9(4), 799-817.

Clarke, M. (1998). Lives in care: Issues for policy and practice in children's homes. Trinity College Dublin: Dublin: Mercy Congregation and The Children's Research Centre. 
Cooper, A. (2005). Surface and depth in Victoria Climbié inquiry report. Child and Family Social Work, 10(1), 1-9.

CORU (2016). Update on the Registration of Social Care Workers. Accessed at: http://www. coru.ie/en/about_us/update_on_the_registration_of_social_care_workers.

Daly, F. (2012). What do young people need when they leave care? Views of care-leavers and aftercare workers in North Dublin. Child Care in Practice, 18(4), 309-324.

Daniel, B. (2003). The value of resilience as a concept for practice in residential settings. Scottish Journal of Residential Child Care, 2(1), 6-15.

Daniel, B., \& Wassell, S. (2002). Adolescence: Assessing and promoting resilience in vulnerable children. London: Jessica Kingsley Publishers.

Daniel, B., Wassell, S., \& Gilligan, R. (2010). Child development for child care and protection workers. London: Jessica Kingsley Publishers.

De Boer, C., \& Coady, N. (2007). Good helping relationships in child welfare: Learning from stories of success. Child and Family Social Work, 12(1), 32-42.

Department of Health (1970). Reformatory and industrial schools systems (1970) report. Dublin: Stationery Report.

Department of Children and Youth Affairs (2015). Review of adequacy in respect of childcare and family support services provided by the Health Services Executive 2013.

Dixon, J. (2008). Young people leaving care: Health, well-being and outcomes. Child and Family Social Work, 13(2), 207-217

Dixon, J., \& Stein, M. (2005). Leaving care: Throughcare and aftercare in Scotland. London: Jessica Kingsley.

Dumaret, A. -C., Donati, P., \& Crost, M. (2011). After a long-term placement: Investigating educational achievement, behaviour, and transition to independent living. Children $\varepsilon$ Society, 25(3), 215-227.

Emond, R. (2005). An outsider's view of the inside. In D. Crimmens, \& I. Milligan (Eds.), Facing forward: Residential child care in the 21st century (pp. 127-136). Lyme Regis: Russell House Publishing.

European Association for Research into Residential Child Care (1998a). Care to listen? A re port of residential child care in four European countries. Available http://www.gifi.es/ administrador/publicaciones/archives/35450_caretolisten.pdf (18th May 2012).

Flores, E., Cicchetti, D., \& Rogosch, A. F. (2005). Predictors of resilience in maltreated and non-maltreated Latino children. Developmental Psychology, 41(2), 38-351.

Fonagy, P. (2002). Psychosocial therapies for young people: Individual approaches Psychiatry, 1(8), 137-140.

Frederico, M., Jackson, A., \& Black, C. (2008). Understanding the impact of abuse and neglect on children and young people referred to a therapeutic programme. Journal of Family Studies, 14(2-3), 342-362.

Gaskell, C. (2009). If the social worker had called at least it would show they cared". Young care leavers' perspectives on the importance of care. Children E Society, 24(2), $136-147$.

Gilligan, R. (1997). Beyond permanence? The importance of resilience in child placement practice and planning. Adoption and Fostering, 21(1), 12-20.

Gilligan, R. (1999). Enhancing the resilience of children and young people in public care by mentoring their talents and interests. Child and Family Social Work, 4(3), 187-196.

Gilligan, R. (2014). The public child and the reluctant state? In M. Luddy, \& J. M. Smith (Eds.), Children, childhood and Irish society 1500 to the present (pp. 145-163). Portland: Four Courts Press.

Health Service Executive (2012a). October 2012 performance report, national service plan. Available http://www.hse.ie/eng/services/Publications/corporate/performancereports/ oct2012pr.pdf (12th December 2015).

Holt, S., \& Kirwan, G. (2012). The "key" to successful transitions for young people leaving residential child care: The role of the keyworker. Child Care in Practice, 18(4), 371-392.

Houston, S. (2010). Building resilience in a children's home: Results from an action research project. Child \& Family Social Work, 15(3), 357-368.

Houston, S. (2011). Using action research to enhance resilience in children's home: An exploration of need, experience and role. Child Care in Practice., 17(2), 115-129.

Howe, D. (1995). Attachment theory for social work practice. London: Palgrave Macmillan.

Howe, D. (1998a). Relationship-based thinking and practice in social work. Journal of Social Work Practice, 16(2), 45-56.

Howe, D. (1998b). Psychosocial work. In R. Adams, L. Dominelli, \& M. Payne (Eds.), Socia work: Themes (pp. 173-183). Basingstoke, Macmillan: Issues and Critical Debates.

Dublin North East, H. S. E. (2010). Policies and procedures for children's residential facilities Dublin: Health Service Executive Accessed at: https://www.hse.ie/eng/services/ publications/Children/Policies\%20Procedures\%20Children‘s\%20Residential\%20Centres. pdf.

Jackson, S., \& Martin, P. (1998). Surviving the system: Education and resilience. Journal of Adolescence., 21(5), 569-583.

Jones, L., Landsverk, J., \& Roberts, A. (2007). A comparison of two caregiving models in providing continuity of care for youth in residential care. Child \& Youth Care Forum $36,99-109$

Kendrick, A. (2008). Residential child care: Prospects E challenges. London: Jessica Kingsley Publishers.

Kendrick, A., Steckley, L., \& Lerpiniere, J. (2008). Ethical issues, research and vulnerability: Gaining the views of children and young people in residential care. Children's Geographies, 6(1), 79-93.

McAuley, C., \& Davis, T. (2009). Emotional well-being and mental health of looked after children in England. Child \&' Family Social Work, 14(2), 147-155.
McClung, M., \& Gayle, V. (2010). Exploring the care effects of multiple factors on the educational achievement of children looked after at home and away from home: An investigation of two Scottish local authorities. Child \& Family Social Work, 15(4), 409-431.

McCrystal, P., \& McAloney, K. (2010). Assessing the mental health needs of young people living in state care using the strengths and difficulties questionnaire. Child Care In Practice, 16(3), 215-226.

McLeod, A. (2010). A friend and an equal: Do young people in care seek the impossible from their social workers? British Journal of Social Work, 40(3), 772-788.

Mallinson, I. (1992). Social care papers for practice: Keyworking in social care, an interim research report. Coventry: SCA education.

Martin, P. Y., \& Jackson, S. (2002). Educational success for children in public care: Advice from a group of high achievers. Child and Family Social Work, 7(2), 121-130.

Miller, D., \& Daniel, B. (2007). Competent to cope, worthy of happiness?: How the duality of self-esteem can inform a resilience base classroom environment. School Psychology International, 28(5), 605-622.

Morrison, S. (2015). In care, aftercare and caring for those in care: My successful care journey. Child Care in Practice Early Online Access.

Munro, E. (2002). Effective child protection. London: Sage Publications.

O'Higgins, A., Sebba, J., \& Luke, N. (2015). What is the relationship between being in care and the educational outcomes of children? An international systematic review. University of Oxford: Rees Centre for Research in Fostering and Education.

O'Sullivan, E. (2009). Part four: Residential child welfare in Ireland, 1965-2008: An outline of policy, legislation and practice: A paper prepared for the commission to inquire into child abuse. (2009) In S. Ryan (Ed.), The report of the commission to enquire into child abuse (pp. 245-430). Dublin: Government Publications.

O'Sullivan, E. (2014). Child welfare services, 1979-80: From the Kennedy committee to the task force. In M. Luddy, \& J. M. Smith (Eds.), Children, childhood and Irish society 1500 to the present (pp. 121-144). Portland: Four Courts Press.

Owusu-Bempah, K. (2010). The wellbeing of children in care: A new approach for improving developmental outcomes. London: Routledge.

Payne, M. (2005). Modern Social Work Theory (3rd ed.). Palgrave: Macmillan.

Pears, K. C., Kim, H. K., Fisher, P. A., \& Yoerger, K. (2013). Early school engagement and late elementary outcomes for maltreated children in foster care. Developmental Psychology, 49(12), 2201-2211.

Perry, D. B., Pollard, A. R., Blakley, L. T., \& Vigilante, D. (1995). Childhood trauma, the neurobiology of the brain: How "states" become "traits". Infant Mental Health Journal, 16(4), 279-291.

Pinkerton, J. (1999). Meeting the challenge: Young people leaving care in Northern Ireland. Ashgate Publishers.

Ruch, G., Turney, D., \& Ward, A. (2010). Relationship based social work. London: Jessica Kingsley Publishers.

Shaw, J. (2011). 'Professionals' perceptions of offending in children's homes. Child and Family Social Work, 17(4), 359-367.

Shaw, J. (2014). Residential children's homes and the youth justice system: Identity, power and perceptions. Basingstoke, Hampshire: Palgrave Macmillan.

Shealy, C. (1995). From Boys Town to Oliver Twist separating fact from fiction in welfare reform and out-of-home placement of children and youth. American Psychologist, 50(8), $565-580$.

Sinclair, I. (2006). Residential care in the UK. In C. McAuley, P. J. Pecora, \& V. Rose (Eds.), Enhancing the well-being of children and families through effective interventions: International evidence for practice (pp. 203-216). London: Jessica Kingsley.

Sinclair, I., \& Gibbs, I. (1998). Children's homes: A study in diversity. Chichester: John Wiley \& Sons.

Skehill, C. (2005). History of the present of child protection and welfare social work in Ireland. New York: Edwin Mellen Press.

Smith, M. (2009). Rethinking residential care. Positive perspectives. Bristol: The Policy Press. Stevens, I. (2004). Cognitive-behavioural interventions for adolescents in residential child care in Scotland: An examination of practice and lessons from research. Child and Family Social Work, 9(3), 237-246.

Townsend, M. (2012). Are we making the grade? The education of young people in out-of home care Retrieved from http://epubs.scu.edu.au/cgi/viewcontent.cgi?article= $1202 \&$ context $=$ theses.

Trevithick, P. (2003). Effective relationship based practice: A theoretical explanation. Journal of Social Work Practice, 17(2), 163-176.

Turney, D. (2012). A relationship-based approach to engaging involuntary clients: The contribution of recognition theory. Child and Family Social Work, 17(2), 149-159.

TUSLA (2016). Integrated performance and activity report quarter 4 2015. Dublin: Quality Assurance Directorate, TUSLA Accessed at: http://www.tusla.ie/uploads/content/ Q4_2015_Integrated_Performance_and_Activity_Report_Final.pdf.

Watson, D. (2002). 'Defining quality care for looked after children: Frontline workers' perspectives on standards and all that? Child and Family Social Work, 8(1), 67-77.

Williams, D., \& Lalor, K. (2001). Obstacles to the professionalization of residential child care work. Irish Journal of Applied Social Studies, 2(3), 73-90.

Woods, M., \& Hollis, F. (2000). Casework: A psychosocial therapy (5th ed.). Boston: McGraw-Hill. 